\title{
Tensile Behaviour of a Structural Adhesive at High Temperatures by the eXtended Finite Element Method
}

\author{
R. D. S. G. CAMPILHO, M. D. BANEA, and L. F. M. DA SILVA
}

\begin{abstract}
Component joining is typically performed by welding, fastening, or adhesive-bonding. For bonded aerospace applications, adhesives must withstand high-temperatures $\left(200^{\circ} \mathrm{C}\right.$ or above, depending on the application), which implies their mechanical characterization under identical conditions. The extended finite element method (XFEM) is an enhancement of the finite element method (FEM) that can be used for the strength prediction of bonded structures. This work proposes and validates damage laws for a thin layer of an epoxy adhesive at room temperature (RT), 100, 150, and $200^{\circ} \mathrm{C}$ using the XFEM. The fracture toughness $\left(G_{\mathrm{Ic}}\right)$ and maximum load $\left(\mathrm{r}^{0}\right)$; in pure tensile loading were defined by testing double-cantilever beam (DCB) and bulk tensile specimens, respectively, which permitted building the damage laws for each temperature. The bulk test results revealed that $f^{0}$ decreased gradually with the temperature. On the other hand, the value of $G_{\mathrm{Ic}}$ of the adhesive, extracted from the DCB data, was shown to be relatively insensitive to temperature up to the glass transition temperature $\left(T_{\mathrm{g}}\right)$, while above $\mathrm{T}_{\mathrm{g}}\left(\right.$ at $\left.200^{\circ} \mathrm{C}\right)$ a great reduction took place. The output of the DCB numerical simulations for the various temperatures showed a good agreement with the experimental results, which validated the obtained data for strength prediction of bonded joints in tension. By the obtained results, the XFEM proved to be an alternative for the accurate strength prediction of bonded structures.
\end{abstract}

KEYWORDS

Bonded joint; eXtended Finite Element Method; Fracture toughness; High temperature adhesives 


\section{INTRODUCTION}

Joining of structural components is typically performed by welding, riveting, fastening, or adhesive-bonding. A number of features make adhesivebonding preferable, or at least competitive, with the more conventional joining methods: reduction of stress concentrations, reduced weight, ability to join different materials, and ease of fabrication and=or automation [1,2]. However, the strength of bonded structures is highly dependent on the load-bearing and long-lasting characteristics of the associated joints [3]. Thus, to fully exploit the advantages of adhesive bonding, damage models must be available that can be reliably employed to predict their fracture behaviour and to minimize design costs and time to market. Structural adhesives for aerospace applications must also be able to keep their mechanical properties at high temperatures. As a result, it is vital for an efficient and quick design process to understand the fracture behavior of these adhesives at high temperatures and to build accurate damage laws that enable a quick analysis of bonded structures by predictive techniques. Such studies are highly important as the strength and fracture toughness are temperature-dependent, especially below and above $T_{\mathrm{g}}[4,5]$. Concerning the strength of adhesives, it is known that at high temperatures weakening is caused by softening and degradation, while at low temperatures the high thermal stresses and the brittleness are the origin of the strength reduction of adhesives. Other generic issues affect the strength of adhesives, such as the surface preparation (that should guarantee a proper bonding to the adherends and avoid adhesive failures, i.e., at the interfaces between the adhesive and components to be bonded [6]), the degree of cure of the adhesive and the curing conditions [7], and the existence of voids and aging=exposure to adverse conditions like moisture or temperature [8]. The fracture toughness is also expected to vary with the temperature, as it is highly dependent on the ductility of the adhesive [9]. The available works concerning the influence of testing temperature on $G_{\text {Ic }}$ of thin adhesive layers in bonded joints are scarce, although the main findings of these studies generally agree quite well. Spingarn [10] evaluated the value of $G_{\text {Ic }}$ of a nylon-modified epoxy adhesive in chevron-notched specimens with aluminium alloy 2024 adherends as a function of the testing rate, adhesive thickness, and temperature, using developed data reduction schemes. The experimental results showed that $G_{\text {Ic }}$ is 
practically insensitive to the testing temperature up to the $T_{\mathrm{g}}$ of the adhesive, drastically reducing above this limit. Lim and Mizumachi [11] addressed the mechanical relaxation mechanism that takes place at $T_{\mathrm{g}}$ on the tensile strength $\left(\mathrm{r}^{0}\right)$; and $G_{\mathrm{Ic}}$ of two epoxy adhesives because of the variation of the viscoelastic properties of the adhesives such as the storage modulus or loss modulus. The analysis of the experimental data showed that both $\mathrm{r}^{0}$ and $G_{\mathrm{Ic}}$ of the two adhesives drastically reduced near $T_{\mathrm{g}}$. Banea et al. [12] used the DCB test to evaluate the temperature dependence of $G_{\mathrm{Ic}}$ for adhesive joints bonded with a high-temperature room temperature vulcanizing (RTV) silicone adhesive, covering a range of temperatures between RT and $260^{\circ} \mathrm{C}$. The experimental determination of the cohesive parameters at different temperatures allowed the definition of triangular cohesive laws that could be subsequently used in FEM simulations to model the fracture of bonded structures. The tensile cohesive laws were obtained by a direct method [13] that consisted of the differentiation of the J-integral $v s$. opening displacement at the crack tip $(J-w)$ curve. The authors concluded that the values of $\mathrm{r}^{0}, G_{\mathrm{Ic}}$, and $w$ decreased with the temperature. The experimental work of Carlberger et al. [14] addressed the $\mathrm{r}^{0}$ and $G_{\text {Ic }}$ dependency on temperature of an epoxy adhesive using the DCBrtest. The tensile cohesive laws of the adhesive were determined by the direct method and the tensile stress, $\mathrm{r}_{n}$ vs. $\boldsymbol{w}$ laws showed an approximate triangular shape. Also, $G_{\text {Ic }}$ was only slightly affected by the testing temperature from 40 to $80^{\circ} \mathrm{C}$, which is consistent with the previous results as the $T_{\mathrm{g}}$ of the a dhesive is nearly $90^{\circ} \mathrm{C}$. On the other hand, $\mathrm{r}^{0}$ gradually diminished with the testing temperature within the selected range of temperatures. This feature, which is common to most structural adhesives in tensile loading $[9,12]$, emphasizes the importance of the availability of the damage laws of adhesives to be used under different temperatures for the design of structures.

The strength prediction of adhesively bonded structures has been studied for several decades, starting with the analytical study of Volkersen [15], which provided an elastic closed-form solution for adhesive layer stresses. FEM codes were afterwards implemented to predict stresses in bonded joints, allowing the simulation of materials' plasticity and complex load cases [16]. The strength approach was initially used for maximum load predictions, but it suffered from mesh dependency [17] since it was based on the comparison of current stresses or strains in the models with the material properties. Fracture mechanics descriptions for failure were an alternative, providing relatively insensitive methods to the presence of singularities, but adding the fracture toughness to the required variables. Cohesive zone modelling (CZM) or XFEM modelling are two relatively recent methods for the prediction of failure in structures, extending the capabilities of traditional fracture methods, by using traction-separation laws between stresses and relative displacements to reproduce damage growth in bulk materials or interfaces between two materials [18]. CZM simulations are based on cohesive elements 
[19] connecting plane or three-dimensional (3D) solid elements at the regions where damage growth is expected, and they do not need an initial defect. Compared with CZM, the XFEM excels in not requiring the crack to grow along the pre-established paths created in the model, and crack growth is permitted anywhere within the bulk regions of the model [20]. The XFEM is implemented over the conventional FEM, and it was developed by Belytschko and Black [21]. It is based on the partition of unity assumption [22], which states that any conventional FEM formulation can be modified by adding local enrichment functions to the nodal displacements at the crack vicinity, thus promoting decohesion [23]. In the XFEM, cracks are modelled as enriched features, simulated by the modification of the degrees of freedom of the nodes near the crack with special displacement functions. As the crack propagates, the crack tip orientation is allowed to change continuously depending on the nearby stresses and, concurrently, enrichment functions are created for the nodal points ahead of the crack tip. In a previous work by the authors [24], the feasibility of the XFEM to predict the strength, load evolution during testing, and crack path in DCB specimens was evaluated at room temperature conditions, considering different adhesives and adherends (material and thickness). In this way, a wide range of adherend restraining conditions was tested, giving varying fracture characteristics (e.g., extent of the fracture process zone) under different adhesive ductilities. The considered adhesives were the ductile epoxy adhesive Araldite ${ }^{\mathbf{1}} 2015$ from Huntsman (Houston, Texas, USA) and the high-temperature adhesive XN1244 from Nagase ChemteX (Shanghai, China). The XFEM model parameters were initially estimated by using standardized tests. The XFEM reproduction of the DCB tests gave a very good match of the tests for all conditions, showing a good agreement between the numerical and experimental load displacement $(P-\mathrm{d})$ curves and crack growth, showing that the XFEM can be a valuable tool in analysing bonded joints under tensile loading.

This work consists of an experimental and XFEM analysis of the tensile behaviour of the high-temperature adhesive XN1244 from Nagase ChemteX at four different temperatures, up to $200^{\circ} \mathrm{C}$, using experimental data from a previously published paper by the authors applied in the context of CZM modeling [9]. The main purpose of the XFEM analysis is to validate this numerical tool for strength prediction of adhesive joints under different temperatures and a pure tensile loading. The DCB geometry was considered for tensile fracture characterization, which is specified in the D3433-99 ASTM standard [25]. To this end, different data reduction techniques are applied to the experimental data to obtain $G_{\text {Ic }}$ at varying temperatures, and the final XFEM parameters under different temperatures are proposed for application to strength predictions at each one of these conditions. The damage laws are then numerically validated to model crack propagation in the adhesive layer at RT, $100^{\circ} \mathrm{C}, 150^{\circ} \mathrm{C}$, and $200^{\circ} \mathrm{C}$, by achieving a good correlation with the experimental joint behaviour. 


\section{MATERIALS USED IN THIS WORK}

The one-component epoxy adhesive XN1244, supplied by Nagase Chemtex and suitable for high-temperature applications, was selected for this study. The $T_{\mathrm{g}}$ and bulk tensile properties of this adhesive such as the Young' $\mathrm{s}$ modulus $(E), \mathrm{r}_{n}^{0}$, and tensile failure strain were estimated in a previous work [26]. $T_{\mathrm{g}}$ was determined to be approximately $155^{\circ} \mathrm{C}$ by dynamical mechanical thermal analysis (DMTA). Definition of the $T_{\mathrm{g}}$ is particularly relevant since, as it is known, only below this temperature do the adhesives keep their indicative properties. Above this temperature, a major strength and stiffness reduction occurs due to degradation of the adhesive [27]. Actually, upon heating the adhesive, the solid polymer transforms from a rigid to a rubbery state. As a result, the molecules that are virtually frozen in position at room temperature begin to undertake rotational and translational motion. Owing to this, an abrupt reduction in the physical properties of the adhesive occurs. The tensile properties of the adhesive XN1244 were determined using dogbone-shaped specimens, produced from bulk adhesive plates cured in a steel mould, using a silicone rubber frame, according to the French standard NF T $76-142$ [28]. Curing of the bulk plates was carried out in a hot plates press $\left(1 \mathrm{~h}\right.$ at $\left.140^{\circ} \mathrm{C}\right)$ at $2 \mathrm{MPa}$ of pressure. The silicone rubber frame allowed the fabrication of $150 \times 5 \mathrm{~mm}$ plates, with a thickness of $2 \mathrm{~mm}$, guaranteeing a good surface finish and demouldability. Tensile testing of the XN1244 specimens was accomplished in a universal testing machine Shimadzu ${ }^{\mathbf{1}}$ Autograph (Kyoto, Japan) with a $5 \mathrm{kN}$ load cell, at a constant velocity of $1 \mathrm{~mm}=$ min. Strains were measured by a video extensometer Messphysik ME46 (Fürstenfeld, Austria), over a length of $50 \mathrm{~mm}$ between hand-painted marks. For the high temperatures, the environmental chamber of the machine was used to apply the thermal load to the specimens. At least three valid results were obtained for each temperature. Table 1 summarizes the mechanical properties extracted from these tests, which will be used in this work to define the material parameters for the FEM simulations. Figure 1 shows, as an example, representative stress-strain (r-e) curves for the tensile tests as a function of temperature of testing. These results report a decrease of strength with the increase of testing temperature, together with an increase in the ductility of the adhesive. For the DCB tests used in this

TABLE 1 Properties of the XN1244 Adhesive by Bulk Tensile Testing

\begin{tabular}{lccc}
\hline & $\begin{array}{c}\text { Young' s modulus, } \\
E[\mathrm{GPa}]\end{array}$ & $\begin{array}{c}\text { Tensile strength } \\
{[\mathrm{MPa}]}\end{array}$ & $\begin{array}{c}\text { Tensile failure } \\
\text { strain [\%] }\end{array}$ \\
\hline $\mathrm{RT}$ & $5.87 \pm 0.33$ & $68.23 \pm 5.06$ & $1.46 \pm 0.23$ \\
$100^{\circ} \mathrm{C}$ & $4.17 \pm 0.89$ & $45.16 \pm 3.44$ & $1.93 \pm 0.43$ \\
$150^{\circ} \mathrm{C}$ & $0.07 \pm 0.01$ & $6.49 \pm 0.86$ & $13.71 \pm 1.46$ \\
$200^{\circ} \mathrm{C}$ & $0.04 \pm 0.02$ & $1.44 \pm 0.17$ & $3.33 \pm 0.2$ \\
\hline
\end{tabular}




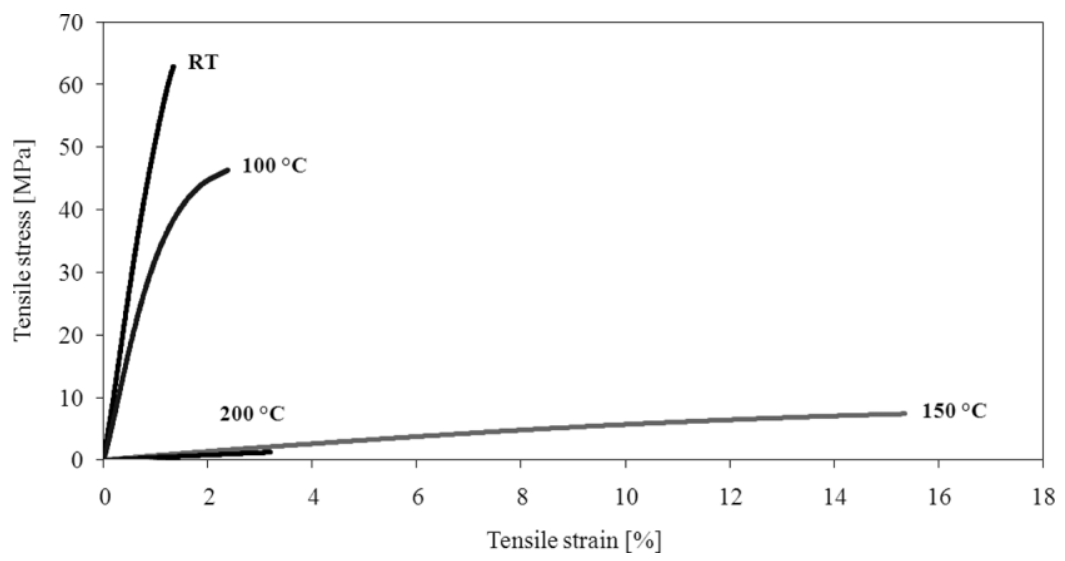

FIGURE $1 \mathrm{r}$-e curves of representative tensile bulk tests to the adhesive XN1244 adhesive as a function of temperature [9].

TABLE 2 Mechanical Properties of the Steel Adherends

Tensile failure strength $[\mathrm{MPa}]$

Yield Stress $[\mathrm{MPa}]$

Elongation $[\%]$

Young' s modulus, $E[\mathrm{MPa}]$

$$
\begin{gathered}
1000-1068 \\
861-930 \\
14-17
\end{gathered}
$$

Temperature

\begin{tabular}{ccc}
\hline $20^{\circ} \mathrm{C}$ & $200^{\circ} \mathrm{C}$ & $400^{\circ} \mathrm{C}$ \\
205000 & 200000 & 185000
\end{tabular}

work to characterize $G_{\mathrm{Ic}}$, hard tool steel (DIN 40CrMnMo7) adherends were employed to guarantee a fully elastic behaviour of the adherends during the tests. The most relevant mechanical properties of the steel DIN 40CrMnMo7 are presented in Table 2, as reported by the manufacturer.

\section{SPECIMENS' FABRICATION AND TESTING}

The DCB specimens' dimensions are presented in Fig. 2. The following values were selected for this work: adherends' length $192.7 \mathrm{~mm}$, adherends' thickness $12.7 \mathrm{~mm}$, adhesive thickness $t_{\mathrm{A}} 1 / 40.2 \mathrm{~mm}$, and initial crack $a_{0}-55 \mathrm{~mm}$. For the preparation of the specimens, the bonding surfaces of the steel adherends were initially subjected to grit blasting and degreasing with acetone, to provide a surface clean and free of contamination that assures a strong bond. Prior to the adhesive application, calibrated steel spacers of $0.20 \mathrm{~mm}$ were inserted at both bonding edges between the adherends to control $t_{\mathrm{A}}$ at $0.2 \mathrm{~mm}$. For the calibrated spacer at the crack tip, three plies were stacked and glued together (making a total thickness of $0.2 \mathrm{~mm}$ ), composed of a $0.1 \mathrm{~mm}$ thick razor blade between $0.05 \mathrm{~mm}$ spacers, to create 


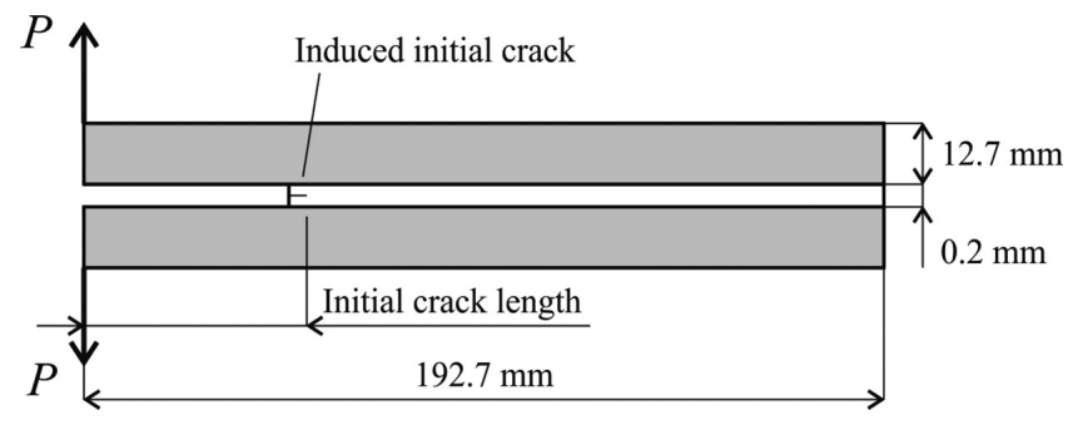

FIGURE 2 Geometry and dimensions of the DCB specimens.

a pre-crack. The adhesive was then poured in both of the adherends of each specimen, which were stacked in a designed mould for the correct alignment during assembly and curing in the press (Fig. 3). After closure of the mould, pressure (2 bar) and high temperature $\left(140^{\circ} \mathrm{C}\right)$ were applied in a hot-plates press during 1 hour. After curing was completed, the steel spacers were removed with pliers, the specimens were slightly loaded in opening in the testing machine, and the value of $\boldsymbol{a}_{0}$ was measured by a high resolution lens. This procedure extends the value of $a_{0}$ by $1-2 \mathrm{~mm}$ from the razor blade crack, and is highly relevant to prevent any blunting that could affect crack propagation in the initial stages. The DCB specimens were then tested at RT, 100,150 , and $200^{\circ} \mathrm{C}$ in a hydraulic testing machine, Instron ${ }^{\mathbf{1}}$ model 8801 (Norwood, Massachusetts, USA), under a constant crosshead rate of $0.5 \mathrm{~mm}=\mathrm{min}$. For the tests at high temperatures, an environmental chamber was used. The $P$-d curves were registered during the tests, and high-resolution photographs were also taken during the specimen' $\mathrm{s}$ testing with $5 \mathrm{~s}$ intervals using a 10 MPixel digital camera, for a correlation with

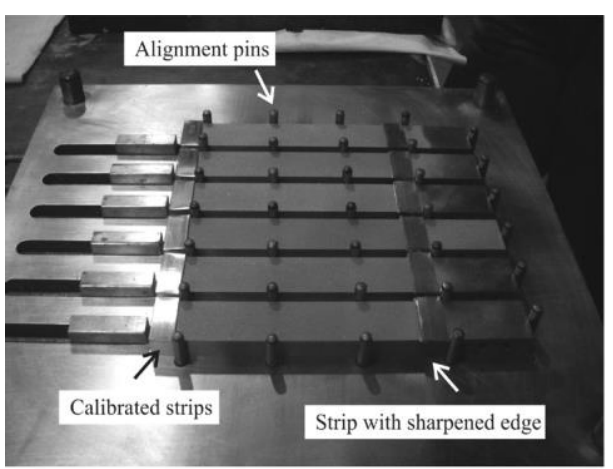

(a)

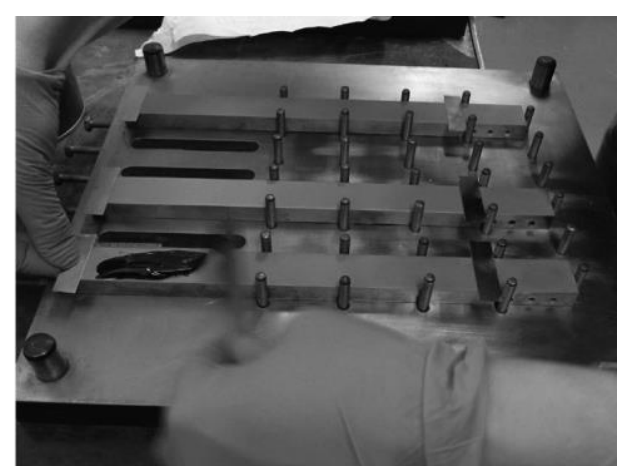

(b)

FIGURE 3 Fabrication of the DCB specimens: (a) lower adherends in the mould for the adhesive application and (b) application of the adhesive. 


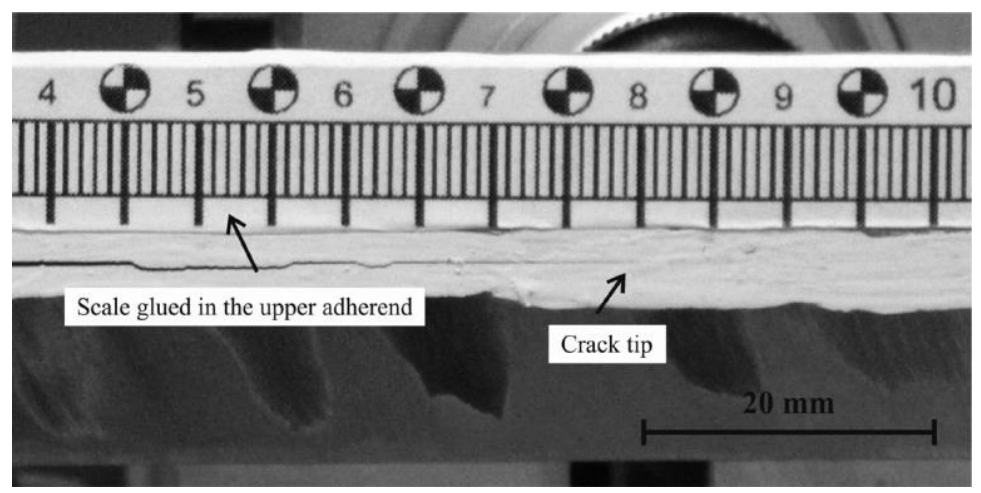

FIGURE 4 Monitoring of $a$ during propagation in a DCB test at RT.

the $P$-d data, allowing the determination of $G_{\mathrm{Ic}}$. This was carried out by the knowledge of the elapsed time from the beginning of the test, which can be easily and accurately related to the $P$-d data, as well as the crack length, $a$, visually inspected in the photographs. Figure 4 shows the procedure for the measurement of the crack during the test. Before the beginning of the tests, a thermocouple was attached to one of the steel adherends of the specimen to assure the consistency between the specimen temperature and the air temperature inside the chamber (used for the machine readings). Each test initiated after approximately 10 minutes of achieving the desired test temperature in the adherends to guarantee a uniform temperature throughout the specimen in the beginning of each test. For each temperature, four specimens were considered.

Figure 5 provides a comparison between representative $P$-d curves at each of the testing temperatures, showing the classical concave shape

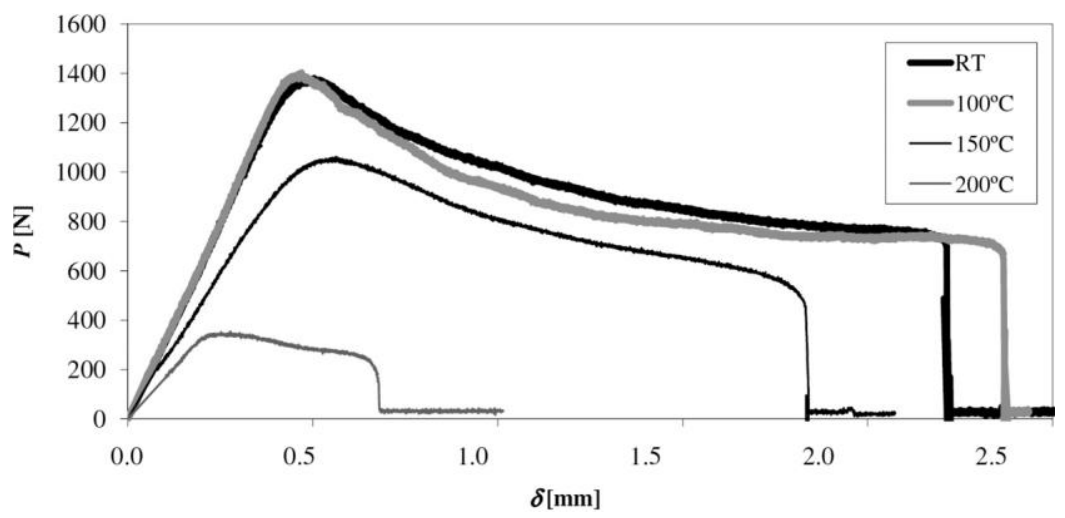

FIGURE 5 Experimental $P$ - $\mathrm{d}$ curves of the DCB tests for the different temperatures, representative of the global results [9]. 


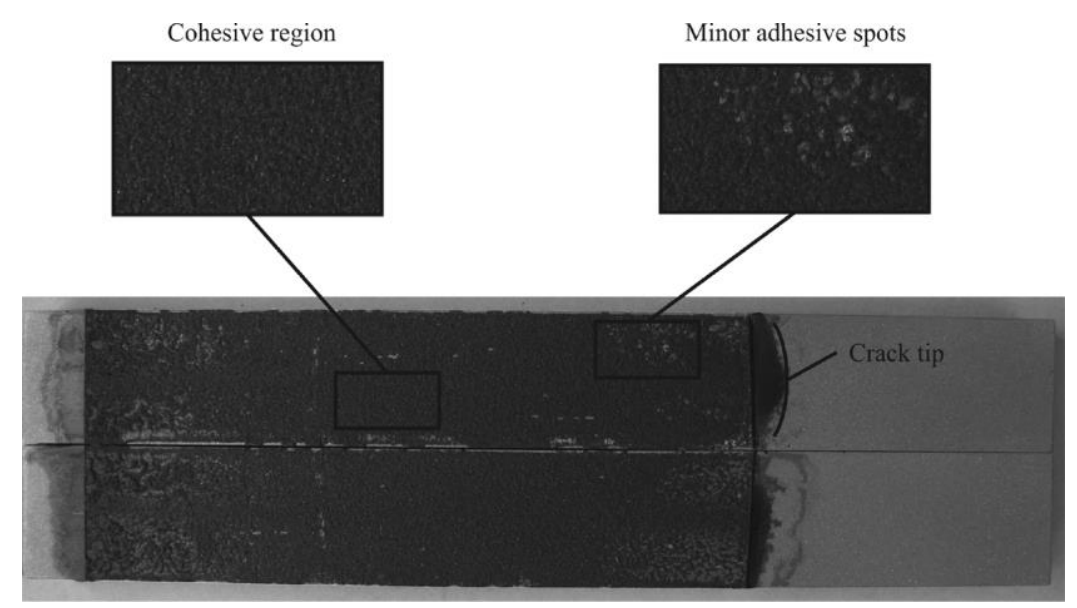

FIGURE 6 Fracture surfaces of a DCB specimen tested at RT.

corresponding to crack growth at a constant $G_{\text {Ic }}$ value [12]. Results at RT and $100^{\circ} \mathrm{C}$ were quite close regarding the initial slope and maximum load, although a slight increase of failure displacement was found at $100^{\circ} \mathrm{C}$. At $150^{\circ} \mathrm{C}$, a moderate reduction of the maximum load took place, accompanied with a reduction of the failure displacement, whilst at $200^{\circ} \mathrm{C}$ the degradation of the adhesive properties owing to the surpassing of $T_{\mathrm{g}}$ was evident. Figure 6 represents a cohesive failure for a specimen tested at RT (with small adhesive spots), which is representative of all specimens tested, regardless of the temperature of testing. All fracture surfaces showed a substantial amount of adhesive in each of the specimens' sides, giving indication of a cohesive failure, although some shifts in the crack path towards one of the adhesive= adherend interfaces were detected in some specimens (as is visible in Fig. 4).

\section{METHODS FOR ESTIMATION OF $G_{\mathrm{IC}}$}

Fracture characterization tests under tensile loading are widely documented and studied in the literature. The most common data reduction schemes to derive $G_{\text {Ic }}$ rely on linear-elastic fracture mechanics (LEFM) principles. The compliance calibration method (CCM) uses the Irwin-Kies equation [29], in which $G_{\mathrm{Ic}}$ at a given testing time depends on the current load, $P$, specimen width, $b$, and current value of $d C=d a(G / 4 \mathrm{~d}=P$ is the specimen compliance, where $\mathrm{d}$ is the displacement). Equally available as LEFM techniques are the direct beam theory (DBT), based on elementary beam theory [30], and the corrected beam theory (CBT), including the effects of crack tip rotation and deflection [31]. As it becomes clear in Fig. 1, the adhesive XN1244 is quite brittle at RT, but it becomes clearly more ductile with increasing temperatures, reaching nearly $13 \%$ of failure strain at $150^{\circ} \mathrm{C}$. This brings some 
issues regarding the applicability of LEFM-based methods, since the fracture process zone can become quite large, and this can make the predicted values of $G_{\text {Ic }}$ inaccurate because of the large-scale plasticity around the crack tip [32]. Despite this fact, for the failure strains observed in Fig. 1, previous works showed that LEFM methods still behave well [33]. Two different methods were employed in this work to evaluate $G_{\text {Ic }}$. The CCM can be calculated as

$$
G_{\mathrm{IC}}=\frac{p^{2}}{2 b} \cdot \frac{d C}{d a}
$$

As is common with this method [33], the $C / 4 f(a)$ curves to obtain $d C=d a$ are reasonably approximated with third order polynomial expressions (e.g., $C^{1 / 4} C_{3} a^{3} \mathrm{p} C_{2} a^{2} \mathrm{p} C_{1} a \mathrm{p} C_{0}$ ), giving

$$
G_{\mathrm{IC}}=\frac{p^{2}}{2 b}\left(3 C_{3} a^{2}+2 C_{2} a+C_{1}\right) .
$$

The CBT states that $G_{\text {Ic }}$ can be extracted from the DCB test by

$$
G_{\mathrm{Ic}}=\frac{3 p \delta}{2 b(a+|\Delta|)}{ }^{\prime}
$$

where D represents the correction to $a$ for consideration of rotation and deflection of the adherends at the crack tip, because the beam theory-based formulation is based on the assumption of clamped adherends at the crack tip. The value of $\mathrm{D}$ can be easily estimated by making a linear regression of $(C)^{1=3} v s$. $a$ data and considering the absolute value of $C^{1 / 4} f(a)^{1 / 4} 0$.

Figure 7 pictures the influence of the testing temperature on $G_{\mathrm{Ic}}$. This parameter attains its maximum at $100^{\circ} \mathrm{C}$, although it is only approximately

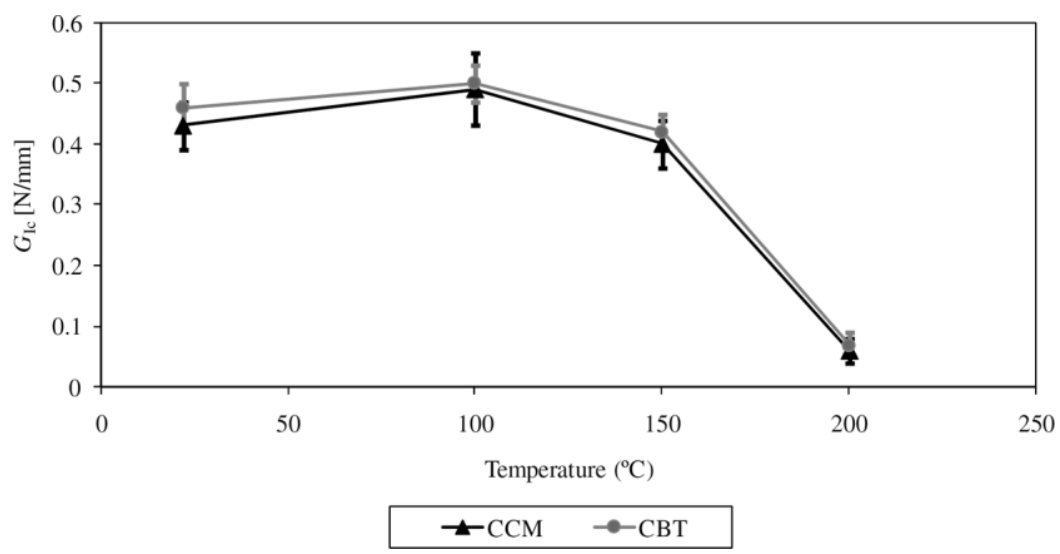

FIGURE $7 G_{\text {Ic }}$ as a function of temperature by the CCM and CBT [9]. 


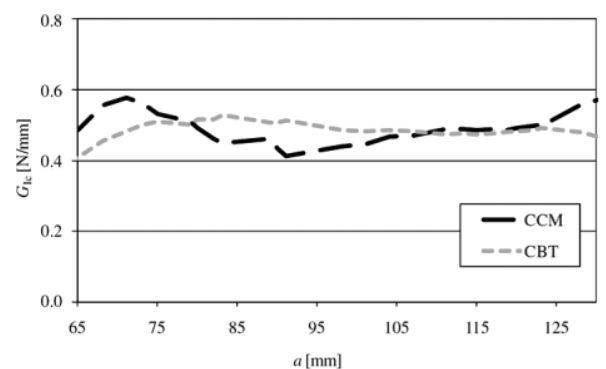

(a)

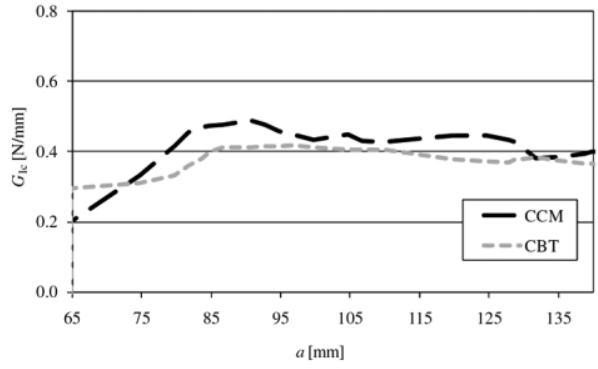

(c)

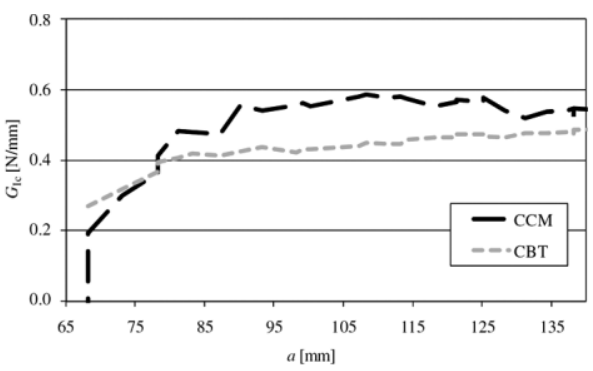

(b)

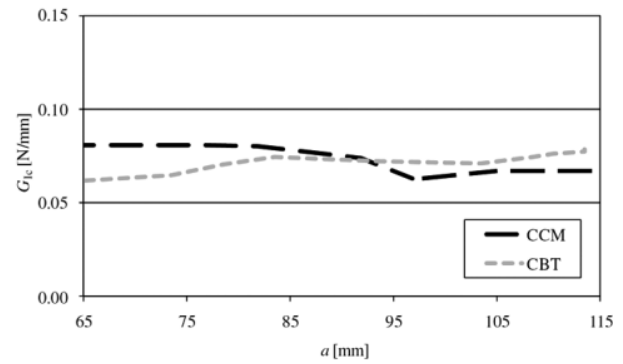

(d)

FIGURE 8 Example of experimental $R$-curves at each temperature: (a; [24]) RT, (b) $100^{\circ} \mathrm{C}$, (c) $150^{\circ} \mathrm{C}$, and (d) $200^{\circ} \mathrm{C}$.

$10 \%$ higher than at RT. Rationale for this apparently odd behavior is given by the slight increase in the adhesive' s ductility (Fig. 1) that increases plastic straining at the crack tip prior to propagation, although the peak strength decreases. At a temperature of $150^{\circ} \mathrm{C}$, the reduction of $G_{\text {Ic }}$ suggests the vicinity of $T_{\mathrm{g}}$, which is afterwards confirmed by the results obtained at $200^{\circ} \mathrm{C}$ that show a complete degradation of the adhesive properties. Figure 8 reports on examples of experimental $R$-curves obtained by the two methods for one specimen at $\mathrm{RT}, 100,150$, and $200^{\circ} \mathrm{C}$, showing crack growth at a nearly constant value of $G_{\mathrm{Ic}}$. The results were quite close between the CCM and CBT, although the former shows some fluctuations that are imputed to polynomial fitting difficulties.

\section{NUMERICAL ANALYSIS}

The FEM software Abaqus ${ }^{\mathbf{1}}$ (Providence, RI, USA), which includes a XFEM module, was considered for the analysis, with the main objective of estimating a damage law for the thin layer of adhesive XN1244 at varying temperatures. Each one of these laws can then be used to simulate the adhesive layer in bonded structures, for an effective strength prediction. Triangular damage laws are considered, i.e., with linear decrease of the transmitted loads after damage initiation, built from the experimental results of the DCB and bulk 
tension tests (the input parameters for the simulations are $E, \mathbf{n}, \mathrm{r}_{n}^{0}$, and $G_{\mathrm{Ic}}$ ). The triangular damage law is the most commonly used law, since it is reliable in simulating materials with different behaviours (from brittle to moderately ductile). The steel adherends were modelled with elastic isotropic conditions, using the generic values of $E$ specified in Table 2 and making linear extrapolations for each testing temperature as a simplification, owing to the small variations of $E$. The simplification of the steel behaviour to elasticity is also only feasible because of the absence of the adherends' plastic flow. Otherwise, the full r-e law of the material should be considered in the simulations. The adhesive layer was considered as an elastic isotropic material up to the attainment of the damage initiation condition. At that point, damage occurred according to the triangular damage law up to complete failure. The numerical analysis considered non-linear geometrical effects to account for second order effects and two-dimensional conditions, which are usually carried out in test geometries that show a constant width-wise shape and that provide an accurate representation of the joint mechanics involved, including damage growth [33]. Figure 9 shows the mesh for the analysis, including details at regions of mesh size grading, as well as the boundary and loading conditions. Restraining and loading conditions included clamping the edge node of the lower adherend, while the edge node of the upper adherend was horizontally restrained and pulled vertically. Particular attention should be paid at this point to establish the boundary and loading conditions such that these faithfully represent the real testing conditions. The meshes were constructed taking advantage of the automatic meshing algorithms of Abaqus $^{\mathbf{1}}$, from a manual seeding procedure that included biasing towards the adhesive bond, because of the stress concentrations that are expected near the adhesive, especially near the fracture process zone [34]. An initial crack was not considered in the numerical models for their simplification, as cracking initiates at the locus of higher magnitude of stresses=strains, as it is mentioned later. Plane strain models were built for the simulations with

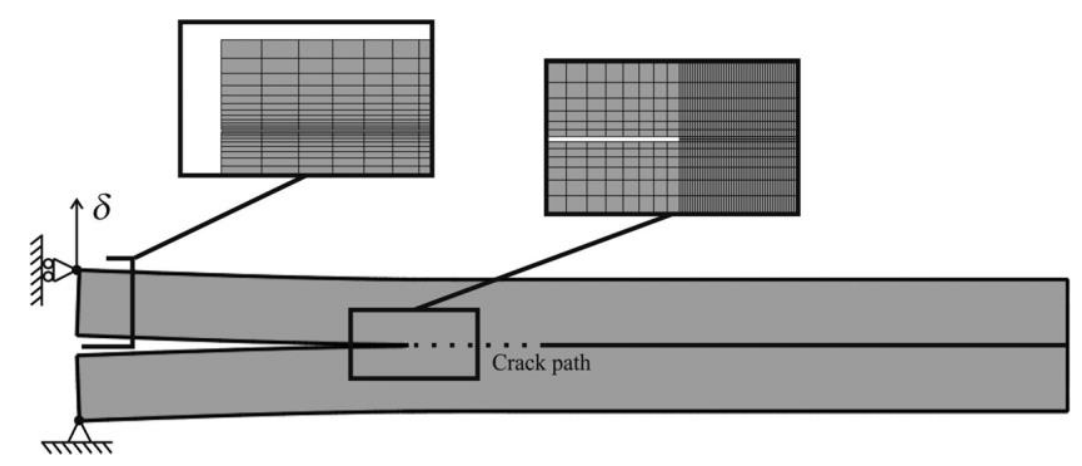

FIGURE 9 Deformed shape of the DCB specimen at the beginning of crack propagation, with boundary and loading conditions (enhancement of the deformations by $20 \mathrm{x}$ ). 
general purpose solid elements (CPE4 from Abaqus ${ }^{\mathbf{1}}$ ). The XFEM formulation that was adopted for this work is implemented in Abaqus ${ }^{\mathbf{1}}$ CAE [35] and it is briefly discussed in the next Section [24].

\section{1. eXtended Finite Element Modelling}

The XFEM considers an initial linear elastic behavior of the materials. Damage and failure are simulated by initiation criteria and damage laws: the damage initiation criteria can rely on the maximum principal stress or strain, which is compared with the corresponding limiting value, while the traction-separation laws that simulate material degradation can be linear or exponential. In this work, a linear degradation law was chosen between $\mathbf{r}_{n}^{0}$ and $w$, with a proportional depreciation of the transmitted stress with $w$, up to complete failure. More information regarding the damage law can be found in reference [35]. Crack propagation will always take place orthogonally to the maximum principal stresses or strains. In this work, the maximum principal stress criterion was selected for damage initiation and a linear softening law was chosen to model the adhesive behaviour [9]. The XFEM is based on the integration of enrichment functions in the FEM formulation, which allow modelling the displacement jump between crack faces that occurs during the propagation of a crack [35]. Modelling of damage propagation is based on the establishment of phantom nodes that subdivide elements cut by a crack, while propagation of an arbitrary crack is made possible by the use of phantom nodes that initially have the same coordinates as the real nodes and that are completely constrained to the real nodes up to damage initiation. In Fig. 10, the element has nodes $\boldsymbol{n}_{1}$ to $\boldsymbol{n}_{4}$. After being crossed by a crack at $U_{C}$, the element is partitioned in two subdomains, $\mathrm{X}_{\mathrm{A}}$ and $\mathrm{X}_{\mathrm{B}}$. The discontinuity in the displacements is made possible by adding phantom nodes ( $\boldsymbol{n}_{1}$ to $\boldsymbol{n}_{4}$ ) superimposed to the original nodes. Each one of the two sub-elements will be formed by real nodes (the ones corresponding to the cracked part) and phantom nodes (the ones

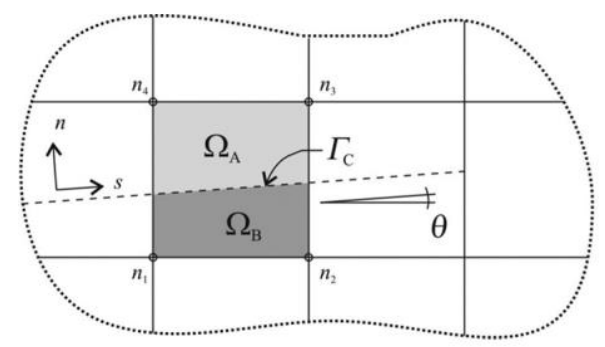

(a)

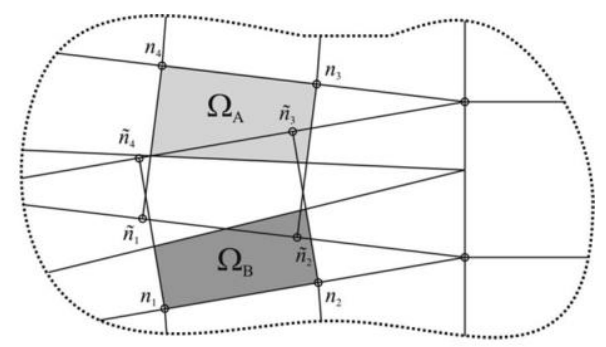

(b)

FIGURE 10 Damage propagation in XFEM using the phantom nodes concept: (a) before and (b) after partitioning of a cracked element into sub-elements [24]. 
TABLE 3 Properties of the Adhesive XN1244 and Steel Adherends for XFEM Modelling

\begin{tabular}{|c|c|c|c|c|c|c|c|c|}
\hline \multirow[b]{2}{*}{ Temperature } & \multicolumn{4}{|c|}{ Adhesive XN 1244} & \multicolumn{4}{|c|}{ Steel } \\
\hline & RT & $100^{\circ} \mathrm{C}$ & $150^{\circ} \mathrm{C}$ & $200^{\circ} \mathrm{C}$ & RT & $100^{\circ} \mathrm{C}$ & $150^{\circ} \mathrm{C}$ & $200^{\circ} \mathrm{C}$ \\
\hline$E[\mathrm{MPa}]$ & 5870 & 4173 & 72 & 40 & $205 \mathrm{e} 3$ & $202,8 \mathrm{e} 3$ & $201,4 \mathrm{e} 3$ & $200 \mathrm{e} 3$ \\
\hline n & 0.35 & 0.35 & 0.35 & 0.35 & 0.3 & 0.3 & 0.3 & 0.3 \\
\hline $\mathbf{r}_{n} 0[\mathrm{MPa}]$ & 68.23 & 45.16 & 6.49 & 1.44 & & & - & \\
\hline$G_{\text {Ic }}[\mathrm{N}=\mathrm{mm}]$ & 0.47 & 0.50 & 0.42 & 0.07 & & & & \\
\hline
\end{tabular}

that no longer belong to the respective part of the original element). These two elements, constituted by the nodes $\boldsymbol{n}_{1}, \boldsymbol{n}_{2}, \boldsymbol{n}_{3}$, and $n_{4}\left(\mathrm{X}_{\mathrm{A}}\right)$ and $\boldsymbol{n}_{1}, \boldsymbol{n}_{2}$, $\boldsymbol{n}_{3}$, and $\boldsymbol{n}_{4}\left(\mathrm{X}_{\mathrm{B}}\right)$, have fully independent displacement fields. From this point, each pair of real=phantom nodes of the cracked element is allowed to separate according to a suitable damage law up to failure. Table 3 summarizes the input parameters of the adhesive layer and steel damage laws introduced in Abaqus ${ }^{1}$.

\subsection{Results}

The XFEM is used in this work to simulate damage propagation in the DCB specimens, and to validate the damage laws and respective parameters, defined for the adhesive at the different testing temperatures by bulk tensile or DCB tests. The validation of the XFEM laws for the adhesive is substantiated if a good correlation is found between the $P$ - $\mathrm{d}$ curves from the DCB tests and the XFEM results. Figure 11 shows the XFEM crack propagation at RT, with crack onset and growth taking place cohesively along the adhesive layer. The aforementioned shifts in the crack path observed in some of the experimental tests (Fig. 4) were not present, as numerically the adhesive is perfectly homogeneous. This failure mode, which is representative of all XFEM propagations occurring at the different temperatures tested, shows that the crack initiates at a roughly intermediate position between the

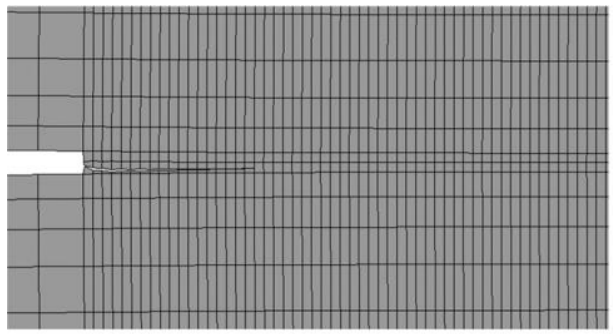

(a)

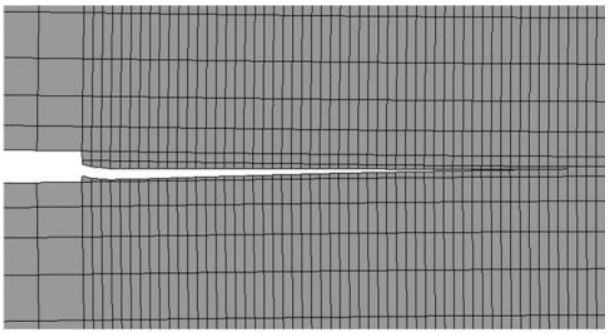

(b)

FIGURE 11 Crack growth at RT by the XFEM algorithm: (a) initiating at the crack tip and (b) growing horizontally along the bondline [24]. 


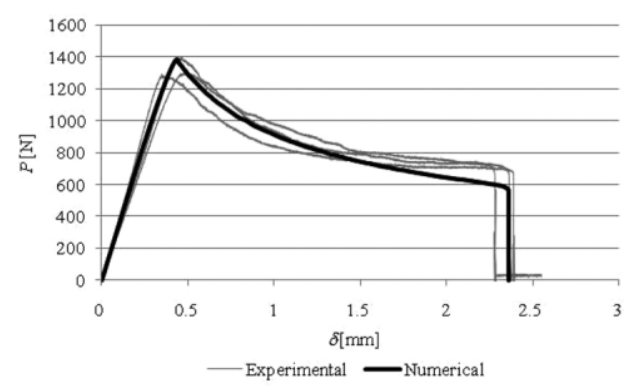

(a)

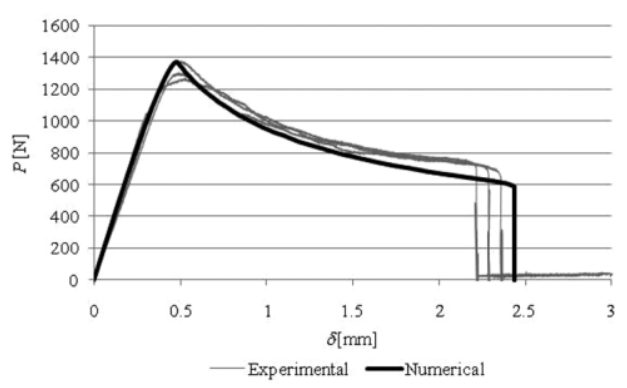

(b)

FIGURE 12 Experimental=numerical $P$-d curves comparison for the DCB specimens at (a; [24]) RT and (b) $100^{\circ} \mathrm{C}$.

adhesive=adherend interfaces and grows cohesively along the adhesive layer, with a slight deviation at the initial part of cracking, but tending to attain the adhesive mid-thickness with further propagation of the crack up to complete failure of the specimen. As previously mentioned, when no initial crack is present, it initiates orthogonally to the maximum principal stress=strain direction, when the maximum principal stress=strain surpasses the material property defined for the analysis. In this example, since this direction is vertical, owing to the pure tensile loading, the crack grows horizontally along the adhesive layer up to failure of the specimen. It should also be mentioned that, if failure for any of the conditions had occurred adhesively at one of the interfaces, this would not be captured by the numerical models, because crack onset and growth is always ruled by stresses and the maximum principal stress direction, providing a cohesive propagation along the middle of the adhesive layer. Figure 12 plots the experimental= numerical $P$-d curve comparisons for the DCB specimens at (a) RT and (b) $100^{\circ} \mathrm{C}$, while Fig. 13 relates to identical curves at (a) $150^{\circ} \mathrm{C}$ and (b) $200^{\circ} \mathrm{C}$. By comparing the maximum loads of the XFEM predictions and experiments

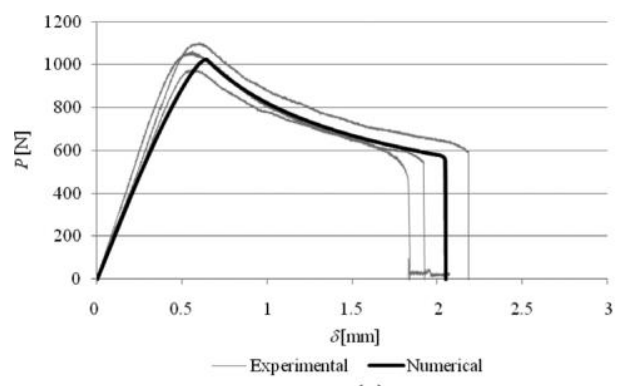

(a)

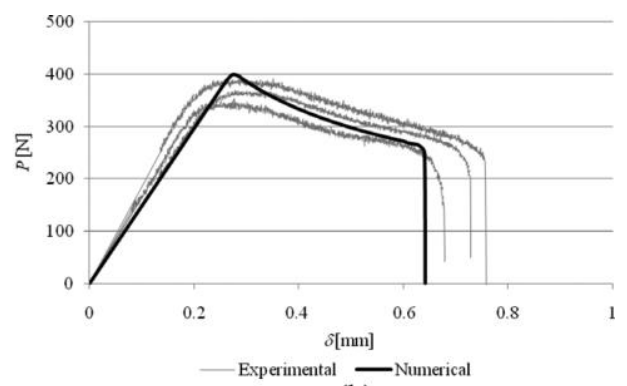

(b)

FIGURE 13 Experimental=numerical $P$-d curves comparison for the DCB specimens at (a) $150^{\circ} \mathrm{C}$ and (b) $200^{\circ} \mathrm{C}$. 
(average values), the following deviations were found: 3.5\% (RT), 4.0\% $\left(100^{\circ} \mathrm{C}\right), 2.6 \%\left(150^{\circ} \mathrm{C}\right)$, and $6.8 \%\left(200^{\circ} \mathrm{C}\right)$. On the other hand, the deviations in the failure displacement were as follows: $1.7 \%(\mathrm{RT}), 6.5 \%\left(100^{\circ} \mathrm{C}\right), 3.2 \%$ $\left(150^{\circ} \mathrm{C}\right)$, and $11.2 \%\left(200^{\circ} \mathrm{C}\right)$. In summary, the elastic stiffness, maximum load, load during propagation, and failure displacement for all conditions using the previously characterized parameters (Table 3) showed a good agreement, which testifies to the suitability of this technique to simulate bonded structures. As a final remark regarding the suitability of the XFEM in reproducing the behaviour of adhesives with different characteristics (i.e., strengths and fracture toughness), it is expected that, provided that the adhesive' $\mathrm{s}$ characterization is carried out under identical conditions to the structure to be simulated, the predictions are accurate. Actually, on one hand, $\mathrm{r}^{0}$ is used in the elastic FEM analyses to detect damage onset region(s) (when the maximum principal stress attains its magnitude anywhere in the model), giving an accurate prediction if the models are properly defined. On the other hand, crack propagation is mainly ruled by $G_{\mathrm{Ic}}$ of the adhesive, which defines the extent of the damage process zone, and whose correct estimation gives a faithful representation of the fracture process taking place near the growing crack, for either small or large values of $G_{\mathrm{IC}}[36]$.

\subsection{Suitability of the XFEM for the Simulation of Bonded Joints}

Although damage propagation with CZM techniques is a powerful and accurate tool $[18,37]$, CZM has a strong intrinsic limitation since cohesive elements to simulate damage growth must be placed at the growth lines where damage is supposed to occur. If damage would occur in another region(s) (e.g., in scenarios of difficult guessing of the damage paths), the correct results would not be provided. However, this limitation is often circumvented by the fact that damage growth in adhesively bonded joints or structures is many times limited to typical locations such as the adhesive= adherend interfaces or within the adhesive itself [38]. This does not occur with the XFEM, as crack propagation is allowed anywhere within the models. However, when speaking about the XFEM formulation of Abaqus ${ }^{\mathbf{1}}$, another drawback appears, because the prediction of damage initiation is based on one value of strength=strain triggering damage initiation (by the maximum principal stress or strain criterion, respectively). This is a limitation in the specific case of thin adhesive layers since their behaviour is not consistent with that of the corresponding bulk adhesives, because of the constraints on deformations imposed by the adherends and respective discrepancies in the stress fields near the crack tip [39]. As a result, if crack growth occurs under mixed-mode conditions, the separation into tensile and shear behaviour that CZM allows is not possible [40]. Apart from this, some crack direction issues can emerge at interfaces between different materials, since the XFEM always propagates cracks orthogonally to the maximum principal 
stresses=strains, which in some cases (e.g., mixed-mode damage propagation) may not correspond to the real behaviour of materials and give inaccurate predictions [41]. In these situations, the XFEM still predicts with accuracy the loci of damage initiation by the stress or strain criteria. Stress singularities that often occur in bonded structures are dealt identically to CZM modelling. Actually, stresses at singular regions never exceed $\mathrm{r}_{n}^{0}$, which implies the suppression of the singularity in the numerical models. Concerning the mesh dependency of the XFEM for the strength predictions, it behaves in an identical manner to CZM, since it is almost mesh independent for the simulation of fracture propagation. This is because the strain energy is averaged over a finite area (the fracture process zone) while crack growth is taking place. Thus, for a large range of mesh sizes, provided that a minimum refinement is used, all the relevant features of the failure process are accurately captured [24]. Despite this fact, given that the prediction of crack initiation is carried out by the value of $\mathbf{r}^{0}$, this feature is mesh dependent, as stresses=strains at concentration regions are mesh dependent as well.

\section{CONCLUDING REMARKS}

In this work, damage laws were derived to model crack propagation of a thin layer of a structural epoxy adhesive in bonded structures at different temperatures (RT, 100,150 , and $200^{\circ} \mathrm{C}$ ) using the XFEM, after determination of the model parameters, $G_{\mathrm{Ic}}$ and $\mathrm{r}^{0}{ }_{n}$ by DCB and bulk tensile tests, respectively. Results of these tests showed that $\mathrm{r}^{0}{ }_{n}$ decreased monotonically with the temperature (showing a steep decrease between 100 and $150^{\circ} \mathrm{C}$ ). The value of $G_{\mathrm{Ic}}$ was found to be relatively insensitive to temperature up to $T_{\mathrm{g}}$, while above $T_{\mathrm{g}}\left(\right.$ at $200^{\circ} \mathrm{C}$ ) a drastic decrease in $G_{\mathrm{Ic}}$ was found. The combined results of these tests showed that bonded joints at $150^{\circ} \mathrm{C}$ may not suffer a drastic reduction of strength, since the $\mathrm{r}^{0}$ reduction at $150^{\circ} \mathrm{C}$ is not accompanied by an identical decrease of $G_{\mathrm{Ic}}$. The DCB specimens used to define $G_{\text {Ic }}$ were then considered for numerical validation of the XFEM procedure to simulate bonded structures, by using the damage laws defined in the characterization tests to reproduce the experimentally obtained $P$-d curves of the DCB tests. The simulation response for the various temperatures tested matched with high accuracy the experimental results, regarding the most relevant features of the joint' $\mathrm{s}$ fracture, as the elastic stiffness, maximum load sustained, transmitted loads during crack growth, and displacement at failure. As a result of these findings, the numerical procedure was validated. With this study, it was also found that, although there are differences between adhesives as a thin layer or as bulk materials, the estimation of the XFEM damage law in tension by bulk tests to obtain the $\mathrm{r}^{0}$ value, which is required for damage initiation prediction, and by DCB tests to obtain $G_{\mathrm{Ic}}$, provides good results for different adhesive conditions, as high 
strength and moderately brittle to low strength and ductile. Moreover, the XFEM can be effectively used to predict the crack onset locations by using stress- or strain-based criteria, although crack growth may not be accurate in the presence of mixed-mode loadings, owing to the considered criterion for this purpose, i.e., based on the principal stress direction. However, as it was shown in this work, crack propagation under a pure tensile loading is correctly modelled, since this leads to crack growth along the adhesive layer. On the other hand, compared with CZM modelling, the restriction to pre-defined fracture paths does not exist, which is a clear advantage when the failure paths are not known beforehand.

\section{ACKNOWLEDGMENTS}

The authors would like to thank Nagase ChemteX (Japan) for supplying the adhesive.

\section{REFERENCES}

[1] Campilho, R. D. S. G., de Moura, M. F. S. F., and Domingues, J. J. M. S., Compos. Sci. Technol. 65, 1948 - 1958 (2005).

[2] Wang, J., Kang, Y. L., Qin, Q. H., Fu, D. H., and Li, X. Q., Comput. Mater. Sci. 43, 1160 - 1164 (2008).

[3] Messler, R. W., Joining of Advanced Materials, (Butterworths=Heinemann, Stoneham, 1993).

[4] Banea, M. D., and da Silva, L. F. M., Proc. IMechE, Part L: J Mater.: Design Appl. $224,51-62$ (2010).

[5] da Silva, L. F. M., and Adams, R. D., J. Adhes. Sci. Technol. 19, 109 - 141 (2005).

[6] Underhill, P. R., and DuQuesnay, D. L., Int. J. Adhes. Adhes. 26, 62 - 66 (2006).

[7] Matsui, K., Int. J. Adhes. Adhes. 10, 277 - 284 (1990).

[8] Park, Y. B., Song, M. G., Kim, J. J., Kweon, J. H., and Choi, J. H., Compos. Struct. 92, 2173 - 2180 (2010).

[9] Banea, M. D., da Silva, L. F. M., and Campilho, R. D. S. G., Int. J. Adhes. Adhes. 31, 273 - 279 (2011).

[10] Spingarn, J., Chevron-notched specimens for measuring adhesive fracture toughness, in "Adhesively-Bonded Joints: Testing, Analysis and Design," ASTM STP 981, W. S. Johnson (Ed.) (American Society for Testing and Materials, Philadelphia, 1988), pp. $69-82$.

[11] Lim, W. W., and Mizumachi, H., Kor. J. Rheol. 8, 129 - 138 (1996).

[12] Banea, M. D., da Silva, L. F. M., and Campilho, R. D. S. G., J. Adhes. Sci. Technol. 24, 2011 - 2026 (2010).

[13] Högberg, J. L., Sørensen, B. F., and Stigh, U., Int. J. Sol. Struct. 44, 8335 - 8354 (2007).

[14] Carlberger, T., Biel, A., and Stigh, U., Int. J. Fract. 155, 155 - 166 (2009).

[15] Volkersen, O., Luftfahrtforschung 15, 41 - 47 (1938).

[16] Tsai, M. Y., and Morton, J., Int. J. Sol. Struct. 31, 2537 - 2563 (1994). 
[17] Feih, S., and Shercliff, H. R., Int. J. Adhes. Adhes. 25, 47 - 59 (2005).

[18] Campilho, R. D. S. G., de Moura, M. F. S. F., and Domingues, J. J. M. S., J. Adhes. Sci. Technol. 21, 855 - 970 (2007).

[19] Petrossian, Z., and Wisnom, M. R., Compos. Part A - Appl. Sci. 29, 503 - 515 (1998).

[20] Mohammadi, S., Extended Finite Element Method for Fracture Analysis of Structures, (Blackwell Publishing, Oxford, UK, 2008).

[21] Belytschko, T., and Black, T., Int. J. Fract. Mech. 45, 601 - 620 (1999).

[22] Melenk, J. M., and Babuska, I., Comput. Method Appl. Mech. Eng. 139, 289 - 314 (1996).

[23] Moës, N., Dolbow, J., and Belytschko, T., Int. J. Numer. Meth. Engng. 46, 131 - 150 (1999).

[24] Campilho, R. D. S. G., Banea, M. D., Chaves, F. J. P., and da Silva, L. F. M., Comput. Mater. Sci. 50, 1543 - 1549 (2011).

[25] ASTM D3433 - 99,Standard test method for fracture strength in cleavage of adhesives in bonded metal joints (ASTM International, West Conshohocken, PA, USA, 2005).

[26] Banea, M. D., da Silva, L. F. M., and Campilho, R. D. S. G., J. Adhes. Sci. Technol. 26, 939 - 953 (2012).

[27] da Silva, L. F. M., and Adams, R. D., Int. J. Adhes. Adhes. 27, 362 - 379 (2007).

[28] NF T 76 - 142, Méthode de preparation de plaques d’ adhésifs structuraux pour la réalisation d' éprouvettes d' essai de caractérisation (1988).

[29] Trantina, G. G., J. Compos. Mater. 6, 192 - 207 (1972).

[30] Kanninen, M. F., and Popelar, C. H., Advanced Fracture Mechanics, (Oxford University Press, Oxford, UK, 1985).

[31] Bonhomme, J., Argüelles, A., Vina, J., and Vina, I., Comput. Mater. Sci. 45, 993 - 998 (2009).

[32] Wang, S. S., J. Compos. Mater. 17, 210 - 223 (1983).

[33] de Moura, M. F. S. F., Campilho, R. D. S. G., and Gonçalves, J. P. M., Compos. Sci. Technol. 68, 2224 - 2230 (2008).

[34] Kuna, M., Comput. Mater. Sci. 13, 67 - 80 (1998).

[35] ABAQUS ${ }^{\mathbf{1}}$ HTML Documentation, Dassault Systemes, Providence, RI, USA (2009).

[36] Sukumar, N., and Prevost, J. H., Int. J. Sol. Struct. 40, 7513 - 7537 (2003).

[37] Benzerga, D., Haddi, A., Seddak, B., and Lavie, A., Comput. Mater. Sci. 41, 515 521 (2008).

[38] Campilho, R. D. S. G., de Moura, M. F. S. F., and Domingues, J. J. M. S., Int. J. Sol. Struct. 45, 1497 - 1512 (2008).

[39] Xie, D., and Waas, A. M., Eng. Fract. Mech. 73, 1783 - 1796 (2006).

[40] Campilho, R. D. S. G., de Moura, M. F. S. F., Pinto, A. M. G., Morais, J. J. L., and Domingues, J. J. M. S., Compos. Part B - Eng. 40, 149 - 157 (2009).

[41] Campilho, R. D. S. G., Banea, M. D., Pinto, A. M. G., da Silva, L. F. M., and de Jesus, A. P. M., Int. J. Adhes. Adhes. 31, 363 - 372 (2011). 